\title{
Synchrotron FTIR Microspectroscopy Study of the Striatum in 6-Hydroxydopamine Rat Model of Parkinson's Disease
}

\author{
Zhu Hongyan, ${ }^{1}$ Pei Xiao, ${ }^{1}$ Wu Lingyan, ${ }^{1}$ Liu Bo, ${ }^{2}$ Qi Zeming, ${ }^{3}$ and Wang Yuyin ${ }^{3}$ \\ ${ }^{1}$ Laboratory of Neuropharmacology and Neurotoxicology, School of Life Sciences, Shanghai University, \\ Nanchen Road 333, Shanghai 200436, China \\ ${ }^{2}$ Shanghai Key Laboratory of Special Artificial Microstructure Materials and Technology, \\ Physics Department, Tongji University, Shanghai 200092, China \\ ${ }^{3}$ National Synchrotron Radiation Laboratory, USTC, Hefei 230026, China
}

Correspondence should be addressed to Zhu Hongyan, zhyred@shu.edu.cn

Copyright (C) 2012 Zhu Hongyan et al. This is an open access article distributed under the Creative Commons Attribution License, which permits unrestricted use, distribution, and reproduction in any medium, provided the original work is properly cited.

\begin{abstract}
In the present study, synchrotron-based Fourier transform-infrared (FTIR) microspectroscopy is used to analyze the biochemical composition of the striatal neurons in normal and Parkinson's disease (PD) rat brain tissues. The rat model of Parkinson's disease is established by destroying the nigrostriatal pathway with 6-hydroxydopamine (6-OHDA). The detailed spectral analyses show the significant changes of cellular compositions such as lipids, and proteins in the striatal neurons of 6-OHDA-lesioned PD rats with respect to control neurons. As a result, the intensities of spectral absorption assigned to lipid of the striatal neurons in PD rats are higher than in control animals. Furthermore, the unsaturation levels of phospholipids decrease in PD neurons with respect to control neurons, indicating a high level of lipid peroxidation. The analysis of protein secondary structure shows the significantly higher ratio of $\beta$-sheet in PD neurons compared to that of control neurons, suggesting that the abnormal protein structure occurs before their morphological appearances in the striatal neurons. These findings suggest that the biochemical changes in neurons could be involved in the pathogenesis of Parkinson's disease.
\end{abstract}

Keywords: Synchrotron FTIR, Parkinson's disease, 6-hydroxydopamine, striatum, and biochemical change

\section{Introduction}

Parkinson's disease (PD) is a chronic, progressive neurodegenerative disorder and characterized by resting tremor, rigidity, slow movement, and other features such as postural and autonomic instability, depression, and cognitive impairment. Pathologically, the main hallmark of PD is the progressive and selective degeneration of the neural connection between the substantia nigra and the striatum, and the dopaminergic neurons in the substantia nigra pars compacta ( $\mathrm{SNpc}$ ). The subsequent dopamine loss in striatum is attributed to the motor symptomatic manifestations of PD. Another crucial pathological feature of PD is the presence of intracytoplasmic inclusions known as Lewy bodies [1, 2]. Although the exact etiology of PD is not clear yet, the genetic and environmental factors have been implicated to 
play a role in the pathogenesis of PD [3]. It has been well documented that mitochondrial dysfunction and oxidative stress are also involved in PD pathogenesis $[4,5]$. 6-OHDA is the first chemical agent discovered that had specific neurotoxic effects on catecholaminergic pathways, and 6-OHDA lesioned rat is a common animal model of PD $[6,7]$. 6-OHDA specifically destroys the unilateral nigrostriatal dopaminergic pathway by being injected into the nigrostriatal tract and produces the degeneration of dopaminergic neurons in ipsilateral SN and near-total depletion of dopamine deficiency in the ipsilateral striatum [8]. While 6-OHDA is transported into neurons, it is rapidly oxidized producing free radicals and hydrogen peroxidase, which affects proteins and membrane lipids [7, 9].

Fourier transform-infrared microspectroscopy (FTIRM) is based on the absorption of infrared light by vibrational transition in covalent bonds to determine molecular chemistry information within biological tissues [10]. FTIRM has the outstanding advantages with synchrotron radiation (SR) infrared source due to its 100-1000 times higher brightness than a conventional thermal infrared source in the mid-IR regime, which can obtain high spatial resolution by achieving diffraction-limited spatial resolution [11-13]. FTIRM directly reflects characteristic changes in molecular composition and structure with disease states in detail by providing the information on vibrational motions of functional molecular groups such as lipids [14-16] and proteins [17, 18]. Numerous studies demonstrated the applications of FTIRM in the biomedical area, such as cell death [19], Alzheimer's disease [20, 21], osteoporosis [22], scrapie [23, 24], the heart disease [25], and others [26]. In human PD patients, FTIRM has been used to investigate the biochemical compositions in the substantia nigra of brain, which reveals that the protein/lipid ratio decreases, while the amide I/amide II ratio increases in PD compared with controls [27].

In this work, the neurotoxin 6-OHDA is microinjected selectively into the unilateral medial forebrain bundle (MFB) to induce the nigrostriatal lesion. The biochemical changes for the neurons of striatum in normal and 6-OHDA-lesioned rat brain tissues are presented by using SR-FTIRM. The main purpose is to construct the relationship between the pathogenesis and biochemical changes for Parkinson's disease.

\section{Materials and Methods}

\subsection{Establishment of 6-OHDA-Lesioned Rat Model of PD}

Adult male Sprague-Dawley rats (Slaccas company, Shanghai) weighing 250-300 g were used. Animals were kept under standard housing conditions in a temperature-controlled room with a $12 \mathrm{~h}$ light-dark cycle and with free access to food and water. Rats were anesthetized by injection (i.p.) of $10 \%$ chloral hydrate and placed in a stereotaxic apparatus (NS-2, Narishige, Japan) with the incisor bar set at $-2.4 \mathrm{~mm}$. A hole was drilled in the scull, and $8 \mu \mathrm{g}$ of 6-hydroxydopamine (Sigma) in $4 \mu \mathrm{L}$ of $0.2 \%$ ascorbic acid with $0.9 \%$ normal saline was infused into the right medial forebrain bundle (MFB) in order to achieve a complete lesion of the nigrostriatal pathway, at the following coordinates (relative to Bregma; see Paxinos and Watson, 1998): AP: $3.2 \pm 0.2 \mathrm{~mm}$, ML: $1.7 \pm 0.1 \mathrm{~mm}$, DV: $8.2 \pm 0.1 \mathrm{~mm}$. Injection speed was $0.5 \mathrm{~mL} / \mathrm{min}$, and the syringe was kept in place for an additional $5 \mathrm{~min}$ before it was slowly retracted. After a 14-day recovery period, rats were prescreened for rotation in response to apomorphine $(0.3 \mathrm{mg} / \mathrm{kg}$, i.p.). Animals that responded to apomorphine ( $\geq 7$ rotations $/ \mathrm{min})$ were used in the SR-FTIR microspectroscopy experiment. 


\subsection{Sample Preparation}

In the present study, seven 6-OHDA-lesioned PD model rats and seven control rats were investigated. All animals were perfused with $4 \%$ paraformaldehyde. After the perfusion, the brains were removed and postfixed in the same fixative solution for $6 \mathrm{~h}$, then immersed in the $30 \%$ sucrose solution until sink to the bottom of container to inhibit the subsequent formation of ice crystals. Typically, the brains were embedded in the frozen section medium Neg-50 (Richard-Allan Scientific, USA), serial $20 \mu \mathrm{m}$ sections including SN were cut on a cryomicrotome (Microm, Germany). One section was selected to histopathological analysis, the next section used in SRFTIR microspectroscopy study was mounted onto $\mathrm{BaF}_{2}$ optical crystals and then dried in air. Five cells were scanned in each sample by synchrotron-based FTIRM.

\subsection{Synchrotron FTIRM}

Infrared microspectroscopy was performed on U4 beamline at National Synchrotron Radiation Laboratory (NSRL, China). The beamline is equipped with a FTIR spectrometer (Bruker IFS $66 \mathrm{v} / \mathrm{s}$ ) which is coupled with an IR microscope (Hyperion 3000). Microspectra were collected in transmission mode using a $20 \mu \mathrm{m} \times 20 \mu \mathrm{m}$ aperture. The spectra were acquired after 512 accumulations at $4 \mathrm{~cm}^{-1}$ spectral resolution. Afterwards, height of selected peaks was used for chemical mapping. Data acquisition and processing were performed using Opus software (Version 5.5).

\subsection{Statistical Analysis}

All data were statistically analyzed by SPSS10.0 software and expressed as mean \pm SEM. MannWhitney $U$ test was used to compare the differences between the control and PD groups. The accepted level of significance for all tests was $P<0.05$.

\section{Results}

SR-FTIR is used to provide a global analysis of organic content of biological samples and the information on molecular structure. The IR micro-spectroscopy analyses are carried out for the striatal neurons of normal and 6-OHDA-lesioned rat brains. The IR absorption spectra of the striatal nerve cell bodies for normal and 6-OHDA-lesioned rats are shown in Figure 1. These spectra are all mainly comprised of characteristic absorption of functional groups, such as lipids and proteins. The assignments of absorption peaks observed in spectra are briefly listed in Table 1. It is found that the spectral profiles in the $3800-3000 \mathrm{~cm}^{-1}$ and $1200-900 \mathrm{~cm}^{-1}$ regions have high sugar-carbohydrate content with respect to that of animal tissues reported in the literature. It could be explained by that sucrose is applied to exert the cryoprotective effect in the brain tissue preparation, which give the high intensity of sugarcarbohydrate. For the 6-OHDA-lesioned samples, the right (lesioned side) and left neurons (unlesioned side) of the striatum are both measured respectively for comparison. The spectra for normal and 6OHDA-lesioned samples exhibit different intensities for each biochemical composition, which implies that the alterations of the relative contents for each composition occur in PD rat model. 
Table 1: Tentative assignments of the bands frequencies present in the IR absorption spectra measured for tissue samples.

\begin{tabular}{|c|c|}
\hline Frequency $\left(\mathrm{cm}^{-1}\right)$ & Assignment \\
\hline $3400-3200$ & $\mathrm{OH}$ str \\
\hline$\sim 3300$ & $\mathrm{~N}-\mathrm{H}$ str (protein and amide $\mathrm{A}$ ) \\
\hline 3080 & $\mathrm{~N}-\mathrm{H}$ str (protein and amide $\mathrm{B}$ ) \\
\hline 2960 & $\mathrm{CH}_{3}$ asym str (lipids) \\
\hline 2924 & $\mathrm{CH}_{2}$ asym str (lipids) \\
\hline 2850 & $\mathrm{CH}_{2}$ sym str (lipids) \\
\hline $1750-1720$ & $\mathrm{C}=\mathrm{O}$ str (ester, lipids) \\
\hline 1655 & $\begin{array}{l}\text { Amide I: } \mathrm{CO} \text { str, } \mathrm{CN} \text { str, and } \mathrm{NH} \text { bend vib } \\
\text { (protein) }\end{array}$ \\
\hline 1545 & Amide II: NH bend vib and CN str (protein) \\
\hline 1460 & $\mathrm{CH}_{2}$ sciss vib; $\mathrm{CH}_{3}$ asym bend vib (lipids) \\
\hline 1380 & $\mathrm{CH}_{3}$ sym bend vib (lipids) \\
\hline 1300 & $\begin{array}{l}\text { Amide III: } \mathrm{CN} \text { str, } \mathrm{NH} \text { bend, } \mathrm{CO} \text { str, and } \\
\mathrm{O}=\mathrm{C}-\mathrm{N} \text { bend vib (protein) }\end{array}$ \\
\hline $1260-1220$ & $\mathrm{PO}_{2}$ asym str (nucleic acids) \\
\hline 1170 & $\mathrm{CO}-\mathrm{O}-\mathrm{C}$ asym str (lipid) \\
\hline 1053 & $\mathrm{PO}_{2}$ sym str (nucleic acids) \\
\hline
\end{tabular}

str: stretching; asym: asymmetric; sym: symmetric; bend: bending; vib: vibration; sciss: scissoring.

Generally, the dominant spectral absorption features for lipids are found in the region 2800$3000 \mathrm{~cm}^{-1}$. In Figure 1, it is found that the absorption intensities of PD neurons in the lesioned side for lipids functional groups at 2850 and $2924 \mathrm{~cm}^{-1}$ belonging to the $\mathrm{CH}_{2}$ symmetric stretching and $\mathrm{CH}_{2}$ asymmetric stretching vibrations, respectively, are over $10 \%$ higher than those of the controls. In addition, the contralateral PD neurons also show a little intensity increase at 2850 and $2924 \mathrm{~cm}^{-1}$ absorption bands with respect to the controls. According to Petibois and Déléris [10, 16], the $\nu=(\mathrm{CH}): \nu_{\mathrm{as}}\left(\mathrm{CH}_{3}\right)$ absorption ratio can indicate the mean unsaturation level of phospholipids, and the $\nu_{\text {as }}\left(\mathrm{CH}_{2}\right): \nu_{\text {as }}\left(\mathrm{CH}_{3}\right)$ absorption ratio provides the mean saturation level of phospholipids, which taken together will provide the measurement of phospholipids peroxidation. Thus, a curve-fitting with a standard Gaussian peak in the $3100-2800 \mathrm{~cm}^{-1}$ spectral interval is performed to quantitatively analyze the ratios of $\nu=(\mathrm{CH}): \nu_{\text {as }}\left(\mathrm{CH}_{3}\right)$ and $\nu_{\text {as }}\left(\mathrm{CH}_{2}\right): \nu_{\mathrm{as}}\left(\mathrm{CH}_{3}\right)$ absorptions (Figure 2). As a result, the ratio of $\nu=(\mathrm{CH}): \nu_{\text {as }}\left(\mathrm{CH}_{3}\right)$ significantly increases in PD neurons both on the lesioned side and unlesioned side compared to that of the controls, as well as the ratio of $\nu_{\text {as }}\left(\mathrm{CH}_{2}\right): \nu_{\mathrm{as}}\left(\mathrm{CH}_{3}\right)$ absorption, shown in Table 2.

The absorption bands at 1653 and $1546 \mathrm{~cm}^{-1}$ correspond to amides I and II and are often used to investigate the various compositions of secondary structures of peptides backbones. From Figure 1, it can be seen that the absorption intensities of the amide I band in the striatal neurons in PD rats both on the lesioned and unlesioned side are evidently decreased with respect to the controls. In order to gain insight into the spectral differences for the secondary structure of proteins between PD and normal samples, the curve-fitting with a standard Gaussian peak analyses in the range of $1800-1500 \mathrm{~cm}^{-1}$ are performed and shown in Figure 3. The results indicate that the compositions of protein secondary structure in 


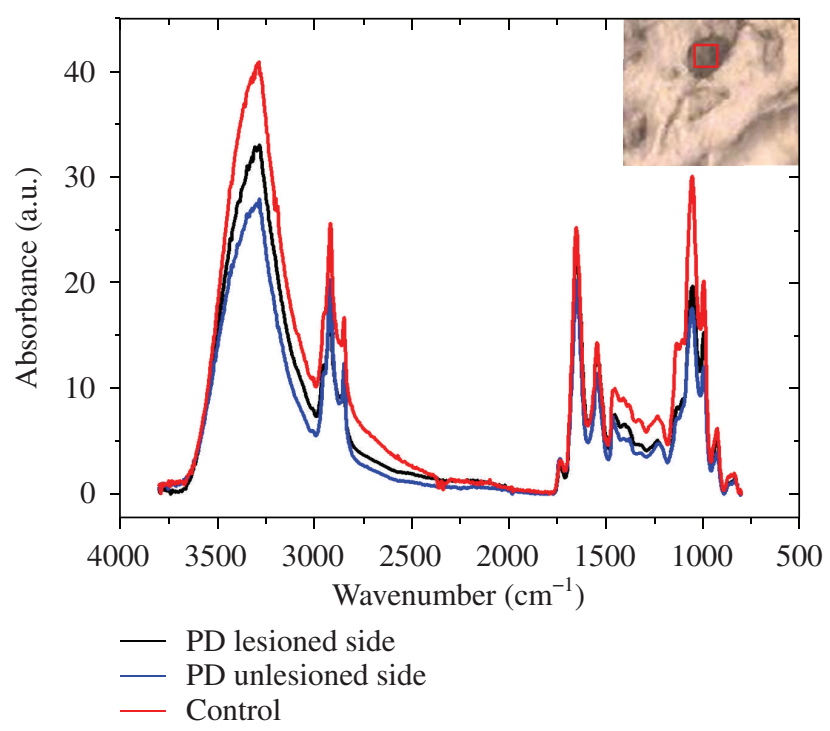

Figure 1: FTIR absorption spectra of the striatal neurons in the controls (red) and 6-OHDA-lesioned PD rats on the lesioned side (black) and unlesioned side (blue). Red rectangle in the insert shows the microscopic view of the scanned neuron in the control sample.

Table 2: The ratios of $\nu(\mathrm{CH}): \nu_{\text {as }}\left(\mathrm{CH}_{3}\right)$ and $\nu_{\mathrm{as}}\left(\mathrm{CH}_{2}\right): \nu_{\text {as }}\left(\mathrm{CH}_{3}\right)$ in the striatal neurons.

\begin{tabular}{|c|c|c|c|}
\hline & Control & PD lesioned side & PD unlesioned side \\
\hline$\nu=(\mathrm{CH}): \nu_{\mathrm{as}}\left(\mathrm{CH}_{3}\right)$ & $0.017 \pm 0.003$ & $\begin{array}{c}0.089 \pm 0.02^{* *} \\
(P=0.001)\end{array}$ & $\begin{array}{c}0.034 \pm 0.006^{* *} \\
(P=0.038)\end{array}$ \\
\hline$\nu_{\text {as }}\left(\mathrm{CH}_{2}\right): \nu_{\mathrm{as}}\left(\mathrm{CH}_{3}\right)$ & $1.27 \pm 0.05$ & $\begin{array}{c}1.53 \pm 0.06^{* *} \\
(P=0.007)\end{array}$ & $\begin{array}{c}1.79 \pm 0.05^{* *} \\
(P=0.001)\end{array}$ \\
\hline
\end{tabular}

\footnotetext{
${ }^{* *}$ Statistically significant differences between control and PD group were marked, the $P$ values of Mann-Whitney $U$ test were
} shown in the parenthesis.

PD neurons are different from that of the controls. The percent ratio of $\alpha$-helix in the amide I region decreases in PD neurons both on the lesioned side and unlesioned side with respect to the controls. In contrast, the percent ratio of $\beta$-sheet highly increases in PD neurons both on the lesioned side and unlesioned side compared to that of the controls (Table 3 ).

\section{Discussion}

The SR-FTIR microspectra exhibit the biochemical composition changes in the striatal neurons of brain in Parkinson's disease model rat. We try to analyse and build the relationship between disease state and neuronal composition changes in lipids and proteins.

The absorption bands at $2820-2996 \mathrm{~cm}^{-1}$ spectral interval assigned to lipid functional groups are analyzed. The intensities of absorbance for lipids in PD neurons are higher than that of the controls. Furthermore, the ratios of $\nu=(\mathrm{CH}): \nu_{\text {as }}\left(\mathrm{CH}_{3}\right)$ and $\nu_{\text {as }}\left(\mathrm{CH}_{2}\right): \nu_{\text {as }}\left(\mathrm{CH}_{3}\right)$ absorption significantly increase in the striatal neurons of $\mathrm{PD}$ on the lesioned side and unlesioned side with respect to those of the 


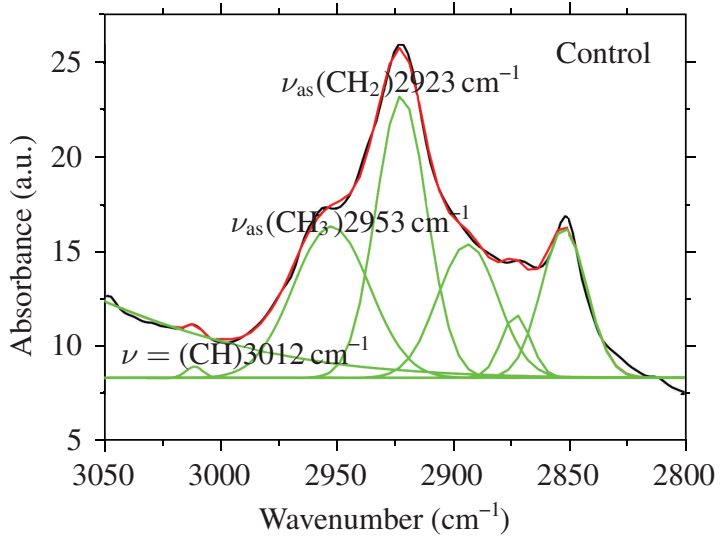

(a)

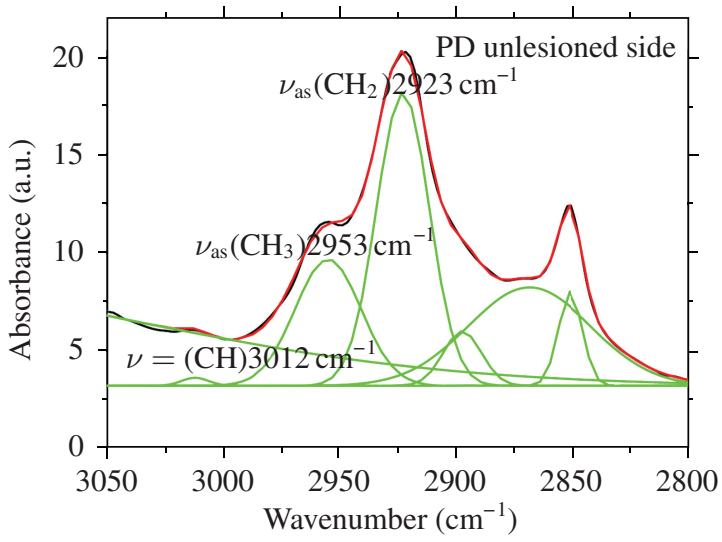

(b)

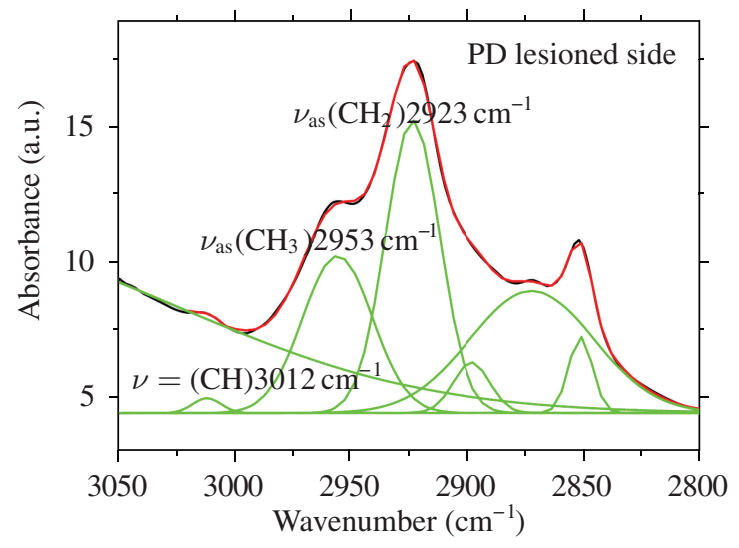

(c)

Figure 2: FTIR absorption spectra of the lipids for the striatal neurons in the control, and PD rats on the lesioned side and unlesioned side. The black line represents experimental data, the green lines represent Gaussian-fitting curves for each component, and the red line represents the sum of fitting curves. (a) control; (b) PD unlesioned side; (c) PD lesioned side.

Table 3: The percentage compositions of protein secondary structure in the striatal neurons.

\begin{tabular}{lccc}
\hline Secondary structure & Control & PD lesioned side & PD unlesioned side \\
\hline \multirow{2}{*}{$\beta$-sheet } & $28.8 \pm 1.6 \%$ & $46.2 \pm 0.89 \%^{* *}$ & $39.4 \pm 0.81 \%^{* *}$ \\
& & $(P=0.001)$ & $(P=0.001)$ \\
$\alpha$-helix & $28.5 \pm 1.5 \%$ & $26 \pm 0.51 \%$ & $25.2 \pm 0.61 \%^{* *}$ \\
\multirow{2}{*}{ Unordered structure } & $42.6 \pm 1.8 \%$ & $27.8 \pm 0.76 \%^{* *}$ & $(P=0.004)$ \\
& & $(P=0.001)$ & $35.3 \pm 0.81 \%^{* *}$ \\
\hline
\end{tabular}

\footnotetext{
** Statistically significant differences between control and PD group were marked, the $P$ values of Mann-Whitney $U$ test were
} shown in the parenthesis. 


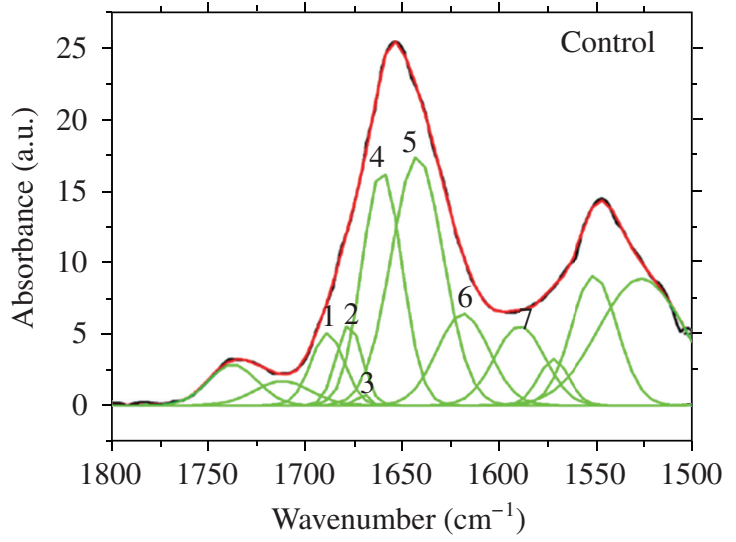

(a)

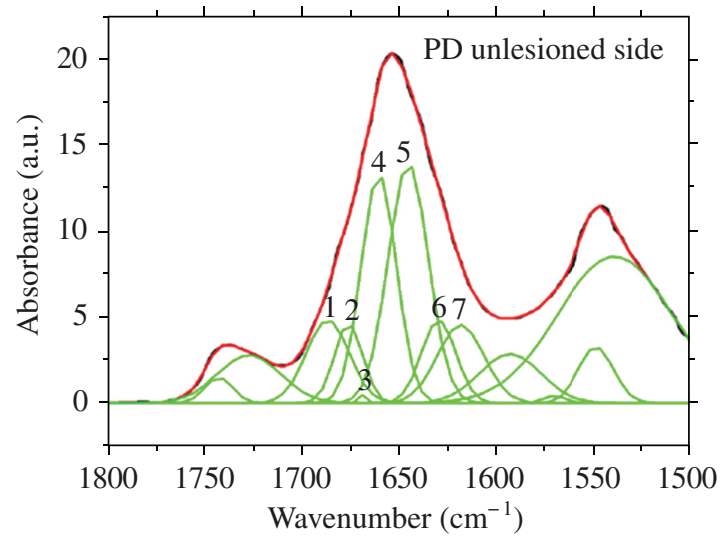

(b)

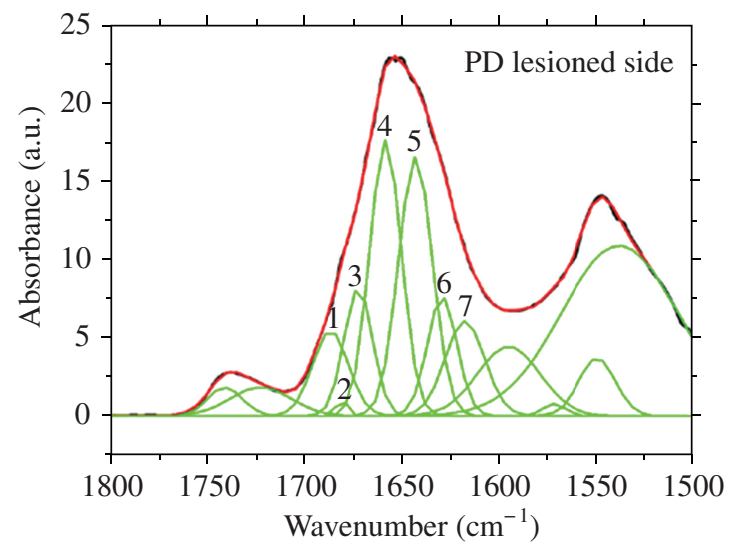

(c)

Figure 3: FTIR absorption spectra of the proteins for the striatal neurons in the controls and PD rats on the lesioned side and unlesioned side. (a) Control; (b) PD unlesioned side; (c) PD lesioned side. The black line is experimental curves, the green lines are fit curves, and the red line is the sum of fit curves. (1) antiparallel $\beta$-strand; (2) parallel $\beta$-strand; (3) $\beta$-turn; (4) $\alpha$-helix; (5) unordered structure; (6) parallel $\beta$-strand; (7) $\beta$-turn.

controls, which points to the decrease of the unsaturation level of phospholipids, thus implicating the high level of lipid peroxidation as a result of oxidation stress $[10,16]$. As we know, the brain has the second highest content of lipids with phospholipids accounting for $6 \%$ of brain dry weight [28]. Among brain lipids, polyunsaturated fatty acids (PUFAs) are particularly vulnerable to oxidation due to their unsaturated bonds. Lipid peroxidation causes a reduction of PUFA content in cell membrane leading to the alterations of membrane properties [29, 30]. Dysregulations of lipids and lipid peroxidation are together regarded as important etiologic factors in the development of PD patients [31, 32]. Animal models of PD have also been implicated in the involvement of oxidative stress. Numerous lines of studies have demonstrated that the neurotoxic effects of 6-OHDA induced the production of reactive oxygen species (ROS) that can damage lipid, protein, and DNA [3, 7, 9]. The present results clearly 
exhibit the change of lipid content and the increase of lipid peroxidation in the striatal neurons of PD model rats induced by 6-OHDA, which is consistent with the aforementioned studies.

Another abnormality for IR analyses is the changes in the secondary structure of proteins for PD animals. The IR spectra of proteins have two primary features: the amide I $\left(1600-1700 \mathrm{~cm}^{-1}\right)$ and amide II $\left(1500-1560 \mathrm{~cm}^{-1}\right)$ bands, the exact frequencies of which are influenced by the strength of hydrogen bonds involving amide $\mathrm{C}=\mathrm{O}$ and $\mathrm{N}-\mathrm{H}$ groups $[33,34]$. The frequency of the amide $\mathrm{I}$ band is particularly sensitive to protein secondary structure $[35,36]$. Protein secondary structure can be determined by the percentages of $\alpha$-helix, $\beta$-sheet, and unordered structure in the amide absorption bands [10]. In this present work, the amide absorption ratios were calculated to demonstrate the conformational changes of protein secondary structure between PD and the control neurons. The results show that the percentage ratio of $\alpha$-helix in PD neurons decreases compared to that in the controls, on the contrary, the percentage ratio of $\beta$-sheet on PD neurons highly increases compared to that in the control. These obtained results indicate the conformational changes of protein in PD neurons. Several lines of literatures show that aberrant protein structures including extracelluar fibrous amyloid deposits and intracellular inclusion bodies are in relationship with neurodegenerative disease. These aberrant protein structures are composed of filamentous, insoluble, protease-resistant structures termed amyloid fibris which have characteristic $\beta$-sheet structure. The main pathological hallmark of Parkinson's disease is cytoplasmic inclusion in the neurons called lewy bodies, the major component of which is suggested as aggregate $\alpha$ synuclein proteins with $\beta$-sheet conformation $[37,38]$. However, this pathological appearance is found to be mainly present in the substantial nigra of PD patients and MPTP models, but not occur in 6-OHDAlesioned animals [39]. The increased ratio of $\beta$-sheet in the striatal neurons of PD animals observed in our studies may reflect the abnormal protein structures involved in the pathogenesis of 6-OHDA-lesioned PD rats.

In conclusion, this study shows that SR-FTIR microspectroscopy can be useful for determining the biochemical changes between PD and normal animals. The main compositions of neuron in PD animals such as lipids, proteins, and nucleic acids are all observed to have changes in content and structure. These changes include the increased content and saturation level of phospholipids, the relatively elevated content of protein secondary structure with $\beta$-sheet. Such results indicate that the changes of biochemical composition detected by SR-FTIR could be involved in the mechanisms of neurodegeneration induced by 6-OHDA. These findings suggest that SR-FTIR microspectroscopy is an accurate and sensitive method to study the pathological changes of neurodegenerative disease.

\section{Acknowledgments}

This work was supported by the National Natural Science Foundation of China (nos. 30900422, 11179019 and 11044011), the National Basic Research Development Program of China (no. 2010CB529806), the Shanghai Science and Technology Commission (no. 11ZR1440500), and Leading Academic Discipline Project of Shanghai Municipal Education Commission-Molecular Physiology.

\section{References}

[1] H. Braak, E. Braak, D. Yilmazer, C. Schultz, R. A. I. De Vos, and E. N. H. Jansen, "Nigral and extranigral pathology in Parkinson's disease," Journal of Neural Transmission, Supplement, no. 46, pp. 15-31, 1995. 
[2] L. S. Forno, "Neuropathology of Parkinson's disease," Journal of Neuropathology and Experimental Neurology, vol. 55, no. 3, pp. 259-272, 1996.

[3] R. Betarbet, T. B. Sherer, D. A. Di Monte, and J. T. Greenamyre, "Mechanistic approaches to Parkinson's disease pathogenesis," Brain Pathology, vol. 12, no. 4, pp. 499-510, 2002.

[4] O. Blin, C. Desnuelle, O. Rascol et al., "Mitochondrial respiratory failure in skeletal muscle from patients with Parkinson's disease and multiple system atrophy," Journal of the Neurological Sciences, vol. 125, no. 1, pp. 95-101, 1994.

[5] D. S. Cassarino, C. P. Fall, R. H. Swerdlow et al., "Elevated reactive oxygen species and antioxidant enzyme activities in animal and cellular models of Parkinson's disease," Biochimica et Biophysica Acta, vol. 1362, no. 1, pp. 77-86, 1997.

[6] R. E. Heikkila, P. K. Sonsalla, and R. C. Duvoisin,12, 351-384, 1989.

[7] C. Sachs and G. Jonsson, "Mechanisms of action of 6-hydroxydopamine," Biochemical Pharmacology, vol. 24, no. 1, pp. 1-8, 1975.

[8] R. L. Faull and R. Laverty, "Changes in dopamine levels in the corpus striatum following lesions in the substantia nigra," Experimental Neurology, vol. 23, no. 3, pp. 332-340, 1969.

[9] A. S. Perumal, V. B. Gopal, W. K. Tordzro, T. B. Cooper, and J. L. Cadet, "Vitamin E attenuates the toxic effects of 6-hydroxydopamine on free radical scavenging systems in rat brain," Brain Research Bulletin, vol. 29, no. 5, pp. 699-701, 1992.

[10] C. Petibois and G. Déléris, "Chemical mapping of tumor progression by FT-IR imaging: towards molecular histopathology," Trends in Biotechnology, vol. 24, no. 10, pp. 455-462, 2006.

[11] W. D. Duncan and Gwyn P. Williams, "Infrared synchrotron radiation from electron storage rings," Applied Optics, vol. 22, no. 18, pp. 2914-2923, 1983.

[12] G. L. Carr, J. A. Reffner, and G. P. Williams, "Performance of an infrared microspectrometer at the NSLS," Review of Scientific Instruments, vol. 66, no. 2, pp. 1490-1492, 1995.

[13] L. M. Miller and R. J. Smith, "Synchrotrons versus globars, point-detectors versus focal plane arrays: selecting the best source and detector for specific infrared microspectroscopy and imaging applications," Vibrational Spectroscopy, vol. 38, no. 1-2, pp. 237-240, 2005.

[14] C. Chen and C. P. Tripp, "An infrared spectroscopic based method to measure membrane permeance in liposomes," Biochimica et Biophysica Acta, vol. 1778, no. 10, pp. 2266-2272, 2008.

[15] J. Chwiej, J. Dulinska, K. Janeczko et al., "Synchrotron FTIR micro-spectroscopy study of the rat hippocampal formation after pilocarpine-evoked seizures," Journal of Chemical Neuroanatomy, vol. 40, no. 2, pp. 140-147, 2010.

[16] C. Petibois and G. Déléris, "Evidence that erythrocytes are highly susceptible to exercise oxidative stress: FT-IR spectrometric studies at the molecular level," Cell Biology International, vol. 29, no. 8, pp. 709-716, 2005.

[17] H. Fabian and D. Naumann, "Methods to study protein folding by stopped-flow FT-IR," Methods, vol. 34, no. 1, pp. 28-40, 2004.

[18] C. Petibois, G. Cazorla, A. Cassaigne, and G. Déléris, "Plasma protein contents determined by fourier-transform infrared spectrometry," Clinical Chemistry, vol. 47, no. 4, pp. 730-738, 2001.

[19] B. Mohlenhoff, M. Romeo, M. Diem, and B. R. Wood, "Mie-type scattering and non-Beer-Lambert absorption behavior of human cells in infrared microspectroscopy," Biophysical Journal, vol. 88, no. 5, pp. 3635-3640, 2005.

[20] L. P. Choo, D. L. Wetzel, W. C. Halliday, M. Jackson, S. M. LeVine, and H. H. Mantsch, "In situ characterization of $\beta$-amyloid in Alzheimer's diseased tissue by synchrotron Fourier transform infrared microspectroscopy," Biophysical Journal, vol. 71, no. 4, pp. 1672-1679, 1996.

[21] L. M. Miller, Q. Wang, T. P. Telivala, R. J. Smith, A. Lanzirotti, and J. Miklossy, "Synchrotronbased infrared and X-ray imaging shows focalized accumulation of $\mathrm{Cu}$ and $\mathrm{Zn}$ co-localized with $\beta$-amyloid deposits in Alzheimer's disease," Journal of Structural Biology, vol. 155, no. 1, pp. 30-37, 2006. 
[22] R. Y. Huang, L. M. Miller, C. S. Carlson, and M. R. Chance, "Characterization of bone mineral composition in the proximal tibia of cynomolgus monkeys: effect of ovariectomy and nandrolone decanoate treatment," Bone, vol. 30, no. 3, pp. 492-497, 2002.

[23] J. Kneipp, P. Lasch, E. Baldauf, M. Beekes, and D. Naumann, "Detection of pathological molecular alterations in scrapie-infected hamster brain by Fourier transform infrared (FT-IR) spectroscopy," Biochimica et Biophysica Acta, vol. 1501, no. 2-3, pp. 189-199, 2000.

[24] J. Kneipp, L. M. Miller, M. Joncic et al., "In situ identification of protein structural changes in prion-infected tissue," Biochimica et Biophysica Acta, vol. 1639, no. 3, pp. 152-158, 2003.

[25] K. M. Gough, D. Zelinski, R. Wiens, M. Rak, and I. M. C. Dixon, "Fourier transform infrared evaluation of microscopic scarring in the cardiomyopathic heart: effect of chronic $\mathrm{AT}_{1}$ suppression," Analytical Biochemistry, vol. 316, no. 2, pp. 232-242, 2003.

[26] L. M. Miller and P. Dumas, "Chemical imaging of biological tissue with synchrotron infrared light," Biochimica et Biophysica Acta, vol. 1758, no. 7, pp. 846-857, 2006.

[27] M. Szczerbowska-Boruchowska, P. Dumas, M. Z. Kastyak et al., "Biomolecular investigation of human substantia nigra in Parkinson's disease by synchrotron radiation Fourier transform infrared microspectroscopy," Archives of Biochemistry and Biophysics, vol. 459, no. 2, pp. 241-248, 2007.

[28] V. Ruiperez, F. Dariosand, and B. Davletov,Prog Lipid Res, 49, 420-428.

[29] A. A. Farooqui and L. A. Horrocks, "Lipid peroxides in the free radical pathophysiology of brain diseases," Cellular and Molecular Neurobiology, vol. 18, no. 6, pp. 599-608, 1998.

[30] S. Waldbaum and M. Patel, "Mitochondria, oxidative stress, and temporal lobe epilepsy," Research, vol. 88, no. 1, pp. 23-45, 2010.

[31] P. Jenner, “Oxidative stress in Parkinson's disease," Annals of Neurology, vol. 53, supplement 53, pp. S26-S36, 2003.

[32] J. Lotharius and P. Brundin, "Pathogenesis of Parkinson's disease: dopamine, vesicles and alphasynuclein," Nature Reviews. Neuroscience, vol. 3, no. 12, pp. 932-942, 2002.

[33] J. Bandekar, "Amide modes and protein conformation," Biochimica et Biophysica Acta, vol. 1120, no. 2, pp. 123-143, 1992.

[34] S. Krimm and J. Bandekar, "Vibrational spectroscopy and conformation of peptides, polypeptides, and proteins," Advances in Protein Chemistry, vol. 38, no. C, pp. 181-364, 1986.

[35] D. M. Byler and H. Susi, "Examination of the secondary structure of proteins by deconvolved FTIR spectra," Biopolymers, vol. 25, no. 3, pp. 469-487, 1986.

[36] H. Susi and D. M. Byler, "Protein structure by Fourier transform infrared spectroscopy: second derivative spectra," Biochemical and Biophysical Research Communications, vol. 115, no. 1, pp. 391-397, 1983.

[37] C. A. Ross and M. A. Poirier, "Protein aggregation and neurodegenerative disease," Nature Medicine, vol. 10, pp. S10-S17, 2004.

[38] A. T. Welzel and D. M. Walsh, "Aberrant protein structure and diseases of the brain," Irish Journal of Medical Science, vol. 180, no. 1, pp. 15-22, 2011.

[39] S. Factor and W. Weiner, Eds., Parkinson s Disease: Diagnosis and Clinical Management, Demos Medical, New York, NY, USA, 2002. 


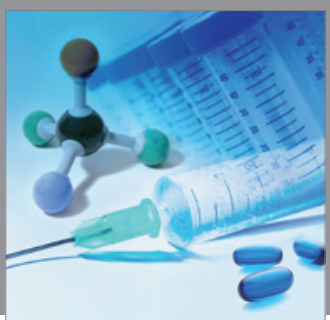

International Journal of

Medicinal Chemistry

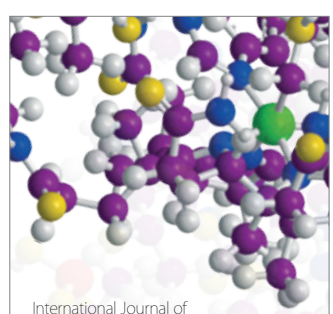

Carbohydrate Chemistry

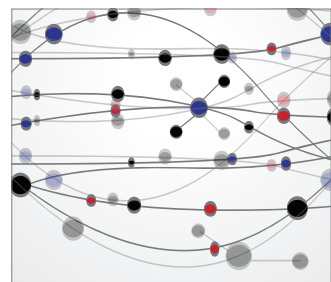

The Scientific World Journal
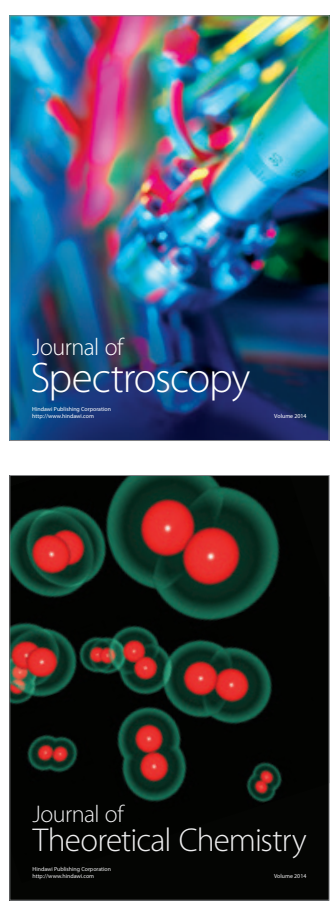
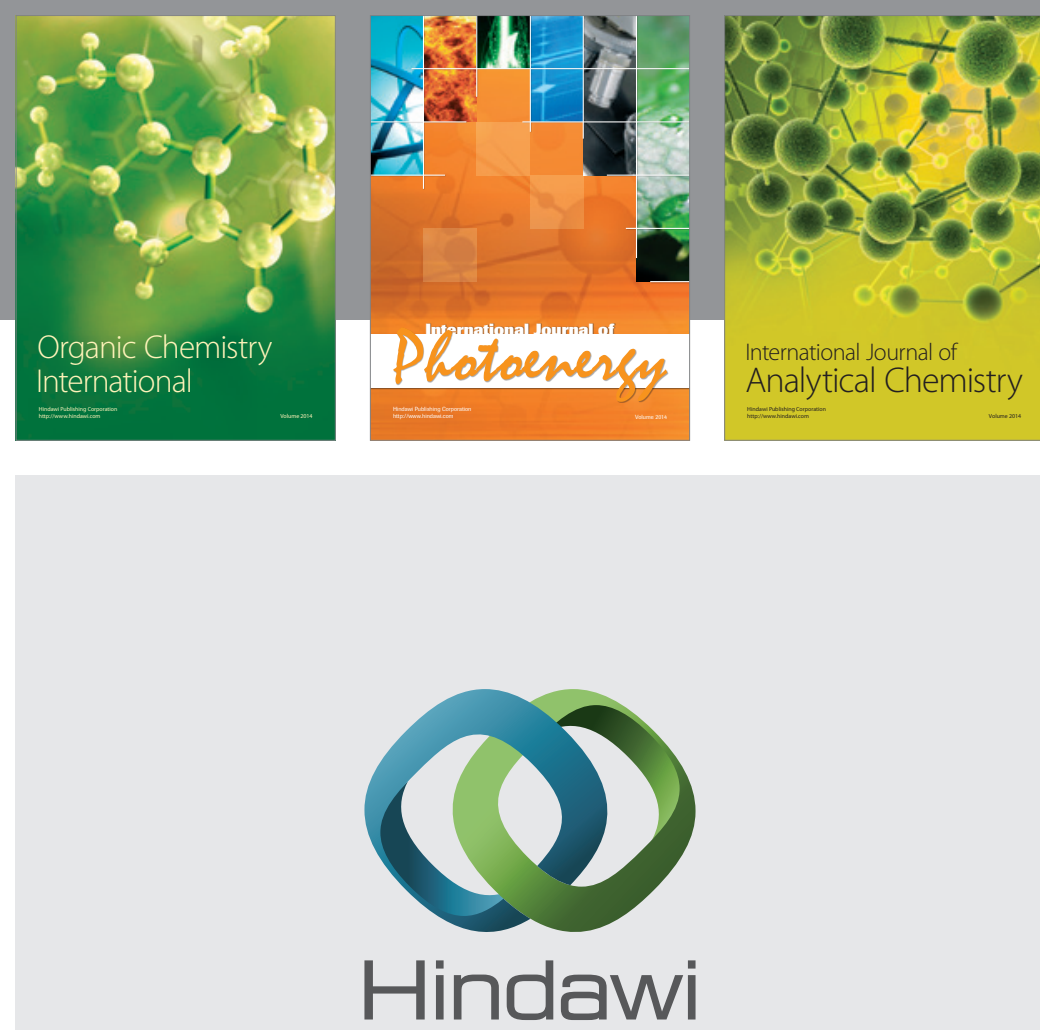

Submit your manuscripts at

http://www.hindawi.com
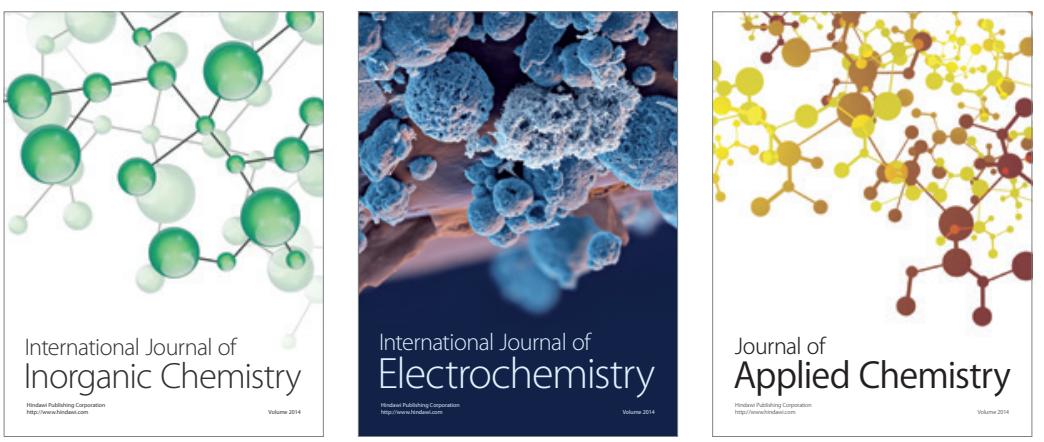

Journal of

Applied Chemistry
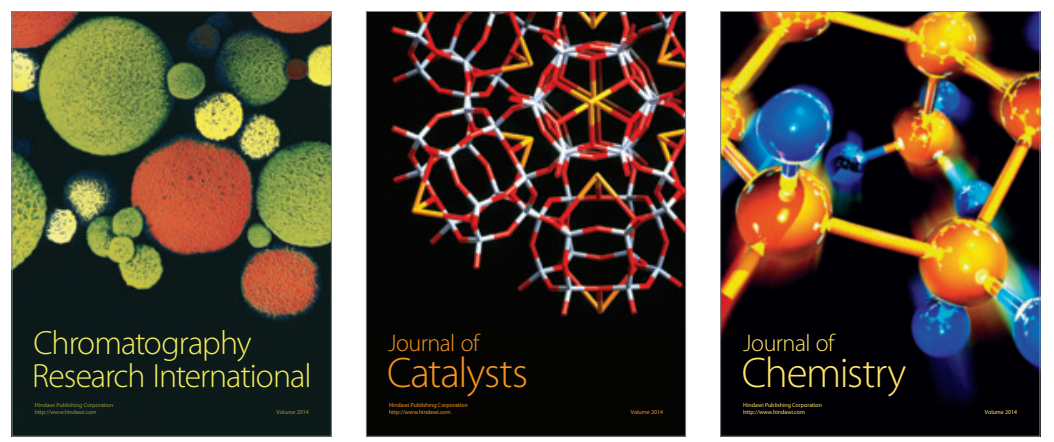
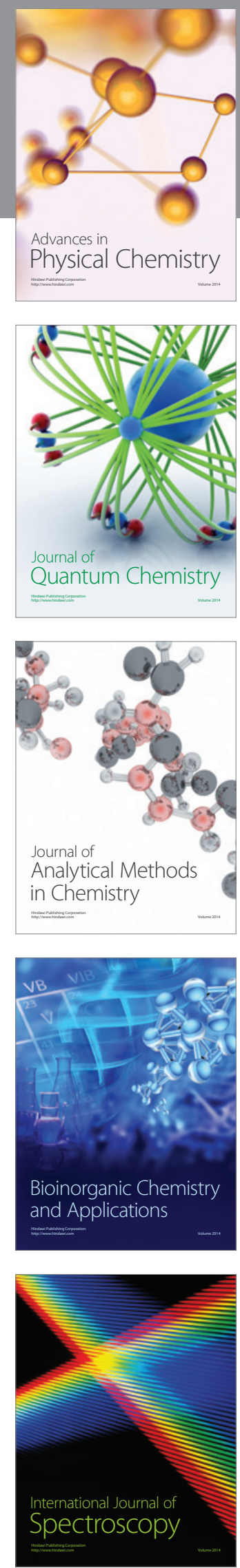